Sensitivity of boreal forests to possible climatic warming.

Kauppi, P.E.

D. Reidel Publishing 1985

Kauppi, P.E. and Posch, M. 1985. Sensitivity of boreal forests to possible climatic warming. Climatic Change 7: 45-54.

http://hdl.handle.net/1975/306

Downloaded from Helda, University of Helsinki institutional repository.

This is an electronic reprint of the original article.

This reprint may differ from the original in pagination and typographic detail.

Please cite the original version. 


\title{
SENSITIVITY OF BOREAL FORESTS TO POSSIBLE CLIMATIC WARMING
}

\author{
PEKKA KAUPPI \\ Finnish Forest Research Institute, Unionink. 40A, SF-00170 Helsinki, Finland \\ and \\ MAXIMILIAN POSCH \\ International Institute for Applied Systems Analysis, A-2361 Laxenburg, Austria
}

\begin{abstract}
General circulation models indicate substantial $\mathrm{CO}_{2}$ warming in high latitudes. In these regions, which include the boreal coniferous forests, the activity of ecosystems is largely controlled by temperature. The effective temperature sum (degree-days) is used in this study for describing the regional variability in the productivity of boreal ecosystems. Although the concept is simple, it takes into account two basic factors: the length of the growing season and the day-to-day level of activity of the ecosystem. This study examines which areas in the boreal coniferous forests would be most sensitive to a possible climatic warming. The data used in the study are for Finland.

A regression is estimated between regional forest growth rate and effective temperature sum. A climatic warming is assumed and the corresponding growth response is calculated, using the regression, for northern and southern areas, and for maritime and continental areas. The response is expressed in terms of (i) absolute increase in growth (grams per $\mathrm{m}^{2}$ per year) and (ii) relative increase in growth. The results indicate that a given climatic warming would yield the greatest absolute increase in growth in warm (i.e. southern) and maritime parts of the biome. In terms of the relative growth response the sensitivity would increase northward and toward maritime areas.
\end{abstract}

\section{Boreal Coniferous Forests}

A large fraction of the Northern Hemisphere at high latitudes is dominated by the boreal biome - a band with a width of more than 1,000 km north-south across the Eurasian and North American continents (Hämet-Ahti, 1981). The area, about 6.7 million $\mathrm{km}^{2}$ depending on the classification criteria, contains roughly $14 \%$ of the world forest biomass (The Global 2000 Report to the President, 1980). The biome is dominated by coniferous forests and has a sparse human population.

The significance of a possible change in the primary productivity of ecosystems as a result of climatic warming can be assessed using alternative indicator variables. The absolute change in productivity can be expressed, for example, in grams of biomass per square meter per year. This can be related to the volume of ecological activities, for example to the annual turnover of the herbivore biomass. However, all ecosystems are adapted to the existing patterns of productivity. Therefore, it is useful to calculate the ratio of the estimated future productivity to the productivity level observed from the historical records, i.e. the relative change in productivity. This variable is expressed as a percentage and describes how dramatic the change would be relative to the historical 
reference level. Both variables are useful for assessing the impact of a possible climatic warming on human societies. The absolute change in productivity would affect the volume of the forest industry, for example. The relative change in productivity could be linked with regional economic activities, and would be an especially useful variable for areas where indigenous forest resources play an important role in the regional economy.

Temperature is a very important ecological factor in the boreal region, both in natural forest ecosystems (Mikola, 1950) and in agroecosystems (Mukula et $a l$, 1978). The productivity of ecosystems is limited over large areas by temperature rather than moisture. A climatic warming should a priori increase the productivity of these ecosystems in both absolute and relative terms.

The response of ecosystems to a climatic change depends on both the character of the change itself - the action - and the character of the ecosystem that produces the reaction. The greatest productivity response would occur in areas where a substantial climatic change - a strong action - coincides with a sensitive ecosystem - a prone reaction. Many uncertainties still exist regarding the action: general circulation models do not yet describe sufficiently accurately the magnitude and geographical distribution of the effects of a possible $\mathrm{CO}_{2}$ warming, and more research is needed. It is nevertheless necessary to focus research simultaneously on the possible reaction.

This study examines the sensitivity of the boreal coniferous forests to a climatic warming that may occur, for example, as a result of $\mathrm{CO}_{2}$ enrichment of the atmosphere. The objective is to find which areas in these forests would be most sensitive - northern or southern parts, forests in continental regions or those in maritime areas.

\section{Effective Temperature Sum}

Even within one biome, the boreal zone, there is large variability in the climate and in the ecosystems. Finland, for example, is entirely classified as a boreal area, and yet the annual average temperature in northern Finland is $5.5^{\circ} \mathrm{C}$ lower than that in the southernmost part of the country. Moreover, a gradient exists with an increasingly continental climate toward the north. Such differences in climate cause substantial variability in ecosystem productivity. A model is needed for relating climate variables to productivity variables. This study focuses on a very large region, and the model must be kept simple. A regression model is introduced that describes the magnitude of the productivity response (absolute or relative) as a function of the effective temperature sum.

The effective temperature sum (ETS) is defined as the cumulative total of the daily average ternperature values that exceed a threshold temperature $T_{0}$. Below that threshold the temperature is not considered 'effective'. The threshold has frequently been fixed at $+5^{\circ} \mathrm{C}$ (Arnold, 1959):

$$
\text { ETS }=\sum_{i=1}^{n}\left(T_{i}-5\right)
$$

where $T_{i}$ is the daily mean temperature and $n$ is the number of days with $T_{i} \geq 5^{\circ} \mathrm{C}$.

The effective temperature sum has been used since de Réaumur (1735) for describing the potential productivity of ecosystems (cited by Sarvas, 1972). The 
variable aggregates information about two important factors: (i) the length of the growing season, and (ii) the day-to-day 'level of activity' of the ecosystem within the growing season. The length of the growing season is described by means of the threshold temperature: days colder than $+5^{\circ} \mathrm{C}$ are omitted. The level of activity within the growing period, i.e above the threshold, is described as a linear function of temperature.

\section{Relating ETS to Forest Growth}

Regional variability of forest productivity cannot be fully ascribed to climatic variability, because soil conditions and, especially, management practices significantly affect productivity. The data used in this study are from Finland, a country extending 1,000 kilometers north-south through the boreal biome. The country is fairly uniform with respect to soil conditions, topography, and land management practices.

A regression is formed between effective temperature sum and tree growth rate, which is closely related to the primary productivity of forest ecosystems. The ETS data are from Kolkki (1969) and the tree growth data are from the National Forest Inventory provided regionally for 19 Forestry Board Districts, which vary in size from 4,000 to $51,000 \mathrm{~km}^{2}$. The inventory data are measured and compiled in about eight-year intervals, the most recent published data being for 1971-76. Earlier data from 1951-53 are used here, because these coincide with the period of the ETS data of Kolkki (1969). (No essential change in forest productivity pattern has been observed between the 1950 s and the 1970 s (Yearbook of Forest Statistics, 1983); see, however, Arovaara et al. (1984).) The tree growth data are based on statistically representative sampling over the whole of Finland. The data are ideal in the sense that they describe regional forest growth, not just the growth of individual forest stands in different parts of the country.

Although it is a simple static model, the regression fits rather well to the observations of regional forest growth (Figure 1). The purpose of constructing the regression model is to generate scenarios of growth in the anticipated warmer climate. A plateau is introduced into the regression, implying that in conditions warmer than those in southernmost Finland today, growth would essentially depend on factors other than temperature. We thus assumed constant growth in high-ETS conditions. On this basis the following relationship is formed between ETS (in degree-days) and tree growth $G$ (in $\mathrm{m}^{3} \mathrm{ha}^{-1} \mathrm{yr}^{-1}$ ):

$$
G=a \cdot E T S-b
$$

with

$$
a=0.0066135, \quad b=3.61157 .
$$

$G$ is set equal to zero if Equation (2) gives a negative value, and $G=6$ if Equation (2) yields a value greater than 6 . This equation is used in the following sections for estimating the sensitivity of forests to a possible climatic warming in different parts of the boreal zone: in maritime and continental parts, and in southern and northern parts. 


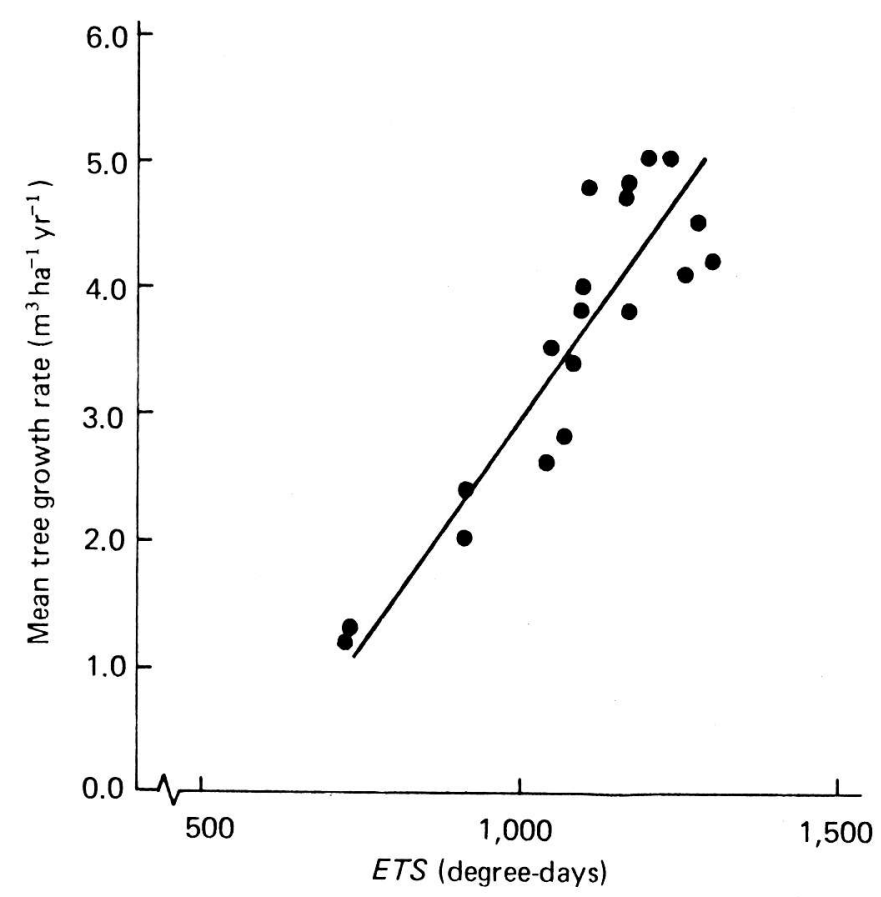

Fig. 1. Regression between the effective temperature sum and the annual mean tree growth rate.

\section{Impacts of Thermal and Maritime-Continental Gradients on ETS}

The annual value of ETS is best calculated by summing the daily values of the effective temperature from the time series data, i.e. by integration of ETS over time. An identical result is obtained by using another method, which can be called integration over temperature distribution. This method is based on the distribution that describes the relative duration of any given temperature within the course of the year (Figure $2 \mathrm{a}$ ). The frequency of each temperature class is weighted by the selected response function and ETS is obtained by adding these weighted frequencies. Both methods for calculating ETS are equally demanding in their data requirements. Daily mean temperatures form the data base also for the second method. However, if an additional simplifying assumption is made, integrating over the temperature distribution provides a basis for expressing ETS as a function of two variables: annual mean temperature and 'degree of continentality'.

A measure for the degree of continentality can be obtained from the temperature frequency distribution. The broader the distribution, the greater the difference between summer and winter temperatures and the more continental the climate. We assume that a normal distribution is suitable for describing the distribution in Figure 2a. This allows us to define the degree of continentality $\sigma$ as the standard deviation of the temperature frequency distribution. Then the 

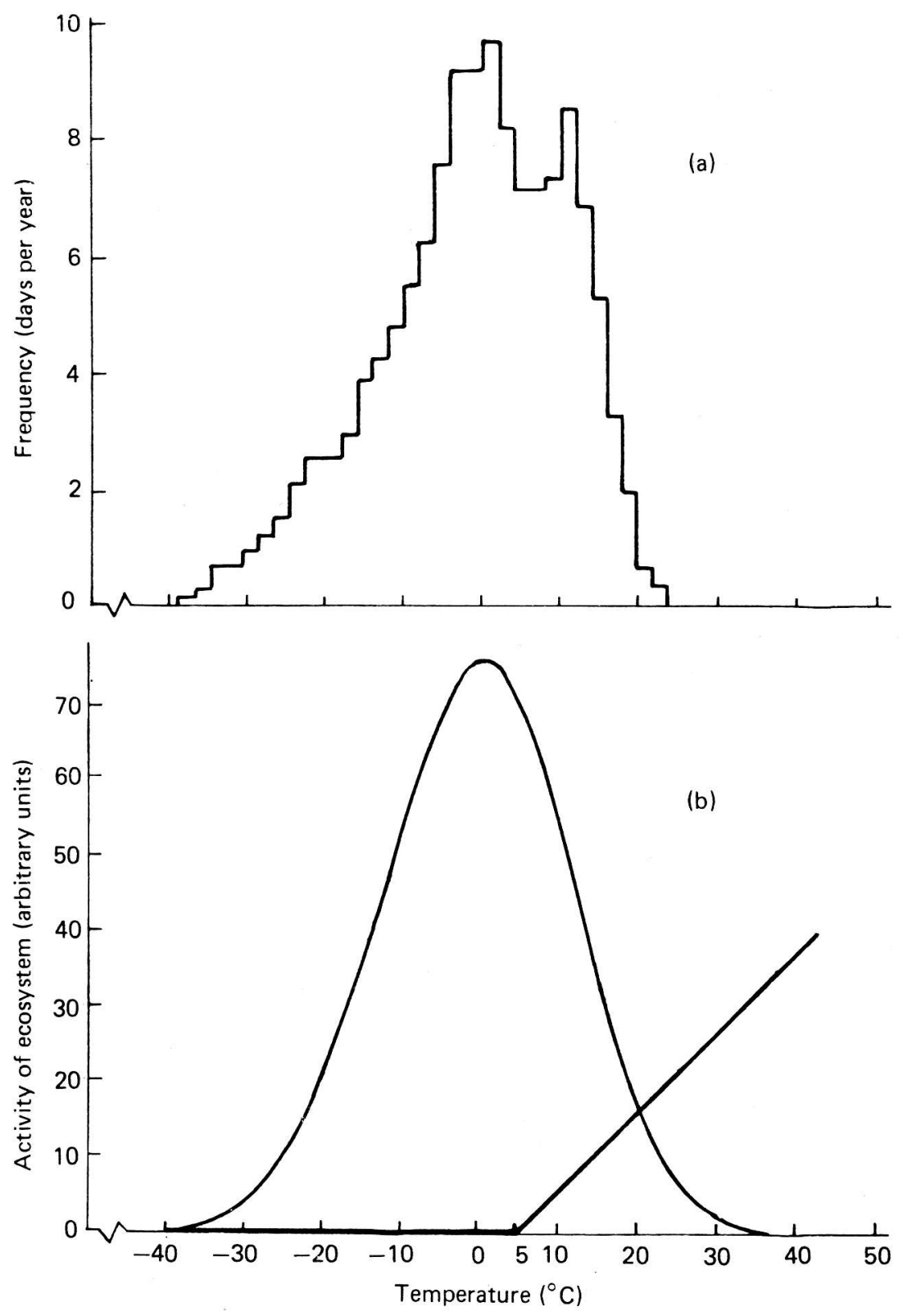

Fig. 2. (a) Temperature frequency distribution over the years 1961-80 in Sodankylä, Finland, longitude $26.5^{\circ} \mathrm{E}$, latitude $67.4^{\circ} \mathrm{N}$ (Heino and Hellsten, 1983). (b) Idealized temperature frequency distribution (of the Sodankylä data), and the response function with $+5^{\circ} \mathrm{C}$ threshold temperature. 
effective temperature sum can be expressed as a function of the number of days $N$ (365), the threshold temperature $T_{0}$, the mean temperature $\bar{T}$, and the degree of continentality $\sigma$ in the following way:

$$
\begin{aligned}
\operatorname{ETS}\left(T_{0}, \bar{T}, \sigma\right) & =\int_{T_{0}}^{\infty}\left(T-T_{0}\right) \frac{N}{\sqrt{2 \pi} \sigma} \exp \left(-\frac{(T-\bar{T})^{2}}{2 \sigma^{2}}\right) \mathrm{d} T \\
& =\frac{N \sigma}{\sqrt{2 \pi}} \exp \left(-\frac{\left(\bar{T}-T_{0}\right)^{2}}{2 \sigma^{2}}\right)+\frac{N}{2}\left(\bar{T}-T_{0}\right)\left[1+\operatorname{erf}\left(\frac{\bar{T}-T_{0}}{\sqrt{2} \sigma}\right)\right],
\end{aligned}
$$

where

$$
\operatorname{erf}(x):=\frac{2}{\sqrt{\pi}} \int_{0}^{x} \mathrm{e}^{-t^{2}} \mathrm{~d} t
$$

$T_{0}$ was fixed in this study at $+5^{\circ} \mathrm{C}$. Equation (3) weights the idealized temperature frequency with the response function and integrates it over temperature. The idealization implies the assumption of a normal distribution (Figure 2b). The significance of this assumption was tested with empirical data from 22 sites in different parts of Finland (data from Heino and Hellsten, 1983). The calculated values of ETS were compared with the corresponding observed values. The fit is sufficient although at the northernmost site Equation (3) overestimates the effective temperature sum by about 15\% (Figure 3 ). The fit suggests that, under Finnish conditions, the assumption regarding the normality of the distribution can be accepted.

Equation (3) describes the impact of mean temperature, or the north-south gradient, and the impact of the standard deviation of the distribution, or the maritime-continental gradient, on the formation of the effective temperature sum. This feature is useful when analyzing the sensitivity of forests to climatic warming along such gradients.

\section{Results}

A uniform $2^{\circ} \mathrm{C}$ increase from baseline levels was selected as an example of climatic warming. The temperature pattern was assumed to remain unchanged. That is, both the winter and summer temperatures were assumed to rise by $2^{\circ} \mathrm{C}$. The growth response to the possible climatic warming was calculated in the following way.

The baseline growth rate $G_{\mathrm{b}}$ was determined for any combination of $\bar{T}$ and $\sigma$, first by computing ETS from Equation (3) and then by using Equation (2) to convert the obtained ETS value to an approximation of the growth rate. The new growth rate after the climatic warming, $G_{n}$, was computed in the same way after adding $2^{\circ} \mathrm{C}$ to the baseline temperatures. Absolute increase in growth was computed as $G_{\mathrm{n}}-G_{\mathrm{b}}$, and the relative increase in growth as $100\left(G_{\mathrm{n}}-G_{\mathrm{b}}\right) / G_{\mathrm{b}}$.

Growth increase, absolute and relative, was expressed as a function of the annual mean temperature $\bar{T}$ and the degree of continentality $\sigma$. Within Finland, $\bar{T}=+4.5^{\circ} \mathrm{C}$ represents a southern area of the boreal. zone and $\bar{T}=-1.0^{\circ} \mathrm{C}$ a northern area. Similarly, $\sigma=8.0^{\circ} \mathrm{C}$ represents a maritime site and $\sigma=13.0^{\circ} \mathrm{C}$ a continental site (Heino and Hellsten, 1983). The maritime extreme is located in 


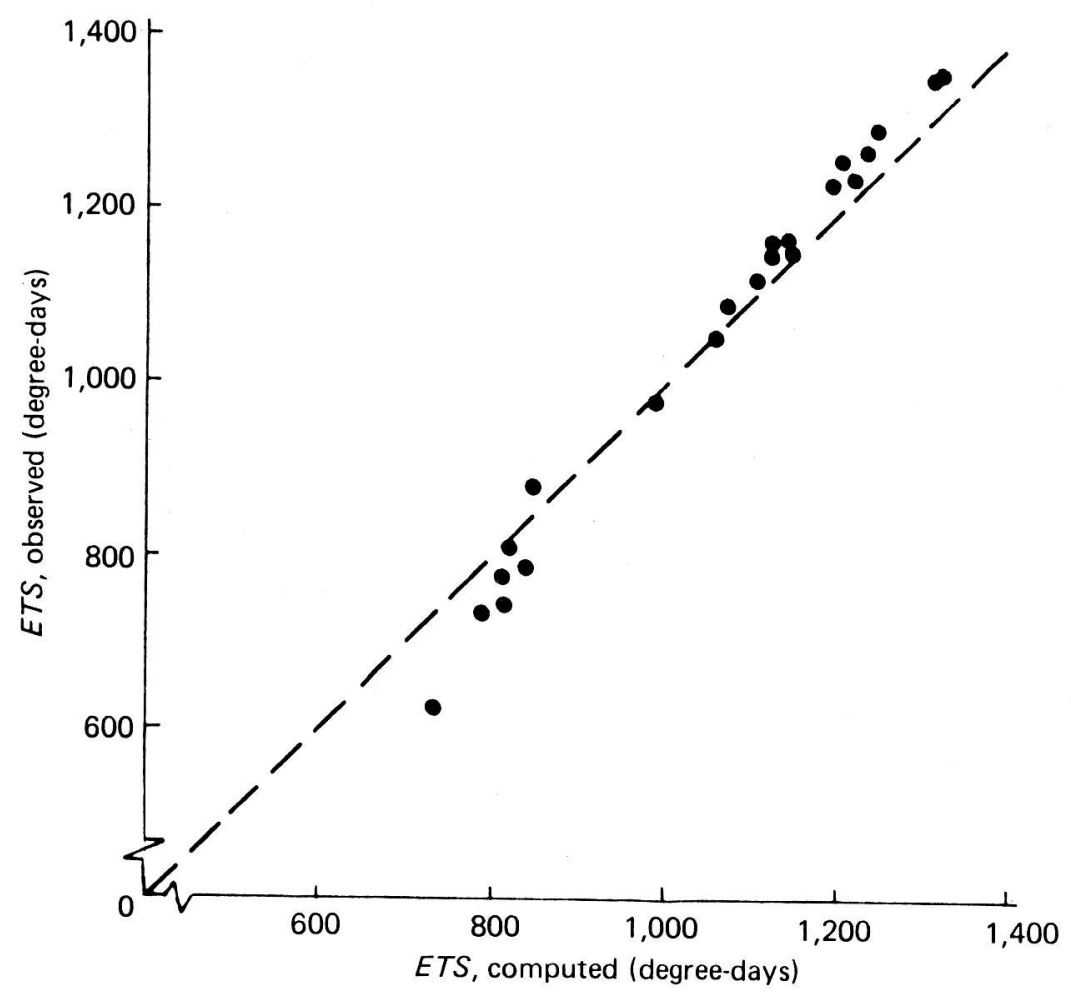

Fig. 3. Calculated and observed values of the effective temperature sum.

southern Finland and the continental extreme in northwestern Finland. Within these ranges the maximum increase of growth, in absolute terms, would occur in southern-central and maritime ecosystems (Figure 4). The relative increase of growth would not have a specific maximum because the baseline growth rate $G_{\mathrm{b}}$ is zero in northern areas. However, given a constant $\sigma$, the relative increase of growth would be the largest in northern (cold) regions (Figure 5). In the same way, given a constant annual mean temperature $\bar{T}$, the relative response would be largest in maritime regions. These qualitative results were tested and found valid in the range of temperature increases from 0.1 to $5^{\circ} \mathrm{C}$.

\section{Discussion}

The response of an ecosystem is jointly determined by the action and by the reaction. The results of Figures 4 and 5 essentially describe the reaction, i.e. the sensitivity of areas to a possible climatic warming. General circulation models indicate that a $\mathrm{CO}_{2}$ warming would not be evenly distributed over the whole land surface (e.g. Manabe and Stouffer, 1980). Therefore a highly sensitive region may not give a high response without an associated large warming. This can be demonstrated with an example. Figures 4 and 5 indicate that coastal 


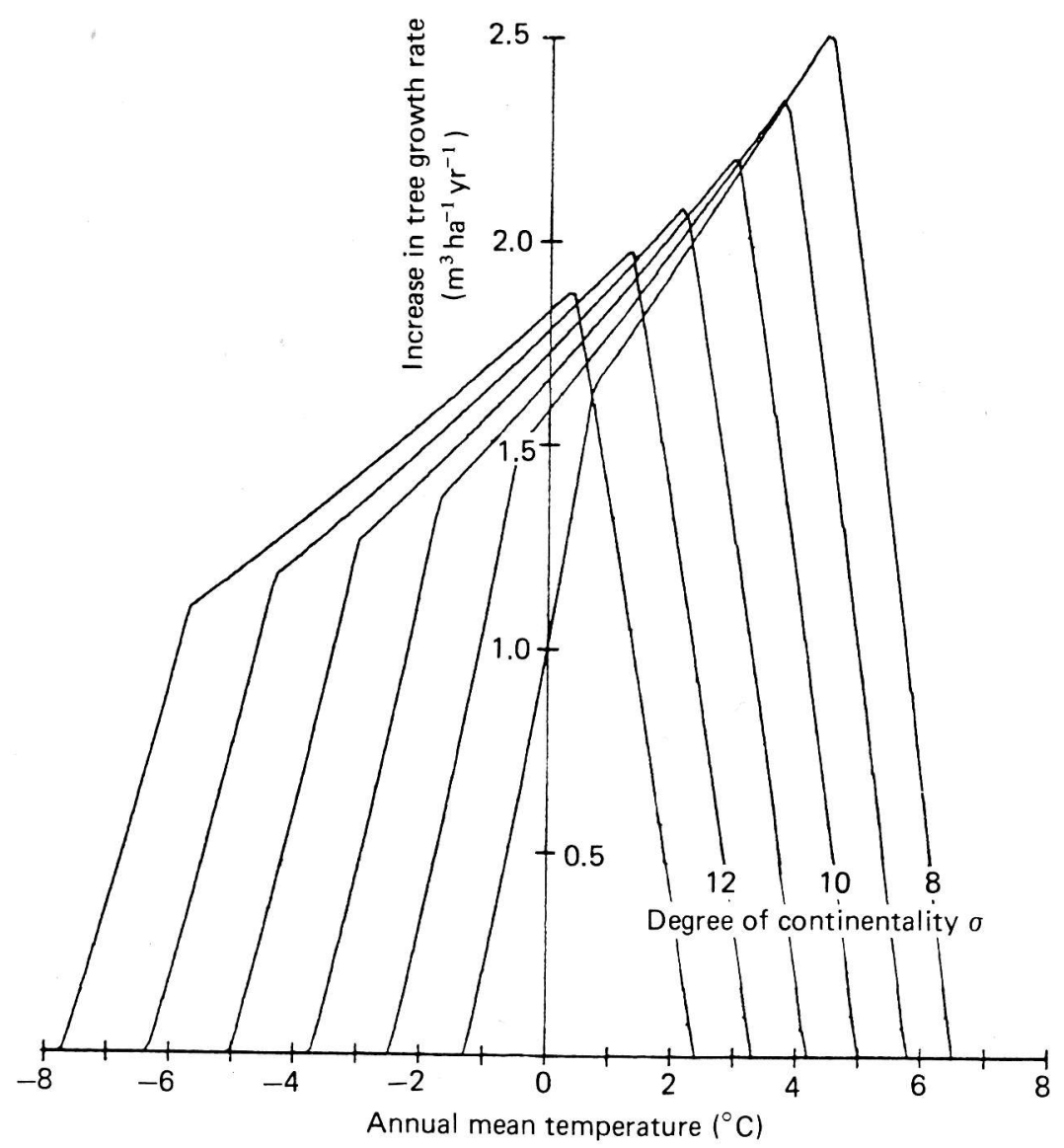

Fig. 4. Calculated growth response to the given $+2^{\circ} \mathrm{C}$ climatic warming as a function of the annual mean temperature $\bar{T}$ and the degree of continentality $\sigma$.

ecosystems would be especially sensitive to climatic warming. However, the possible warmirg in these areas may well be small compared with that in continental areas, and might therefore induce only a moderate response in these highly sensitive ecosystems.

The analysis in this study includes several sources of uncertainty. The selected productivity variables describe only some aspects of the real life of the boreal biome. They do not take into account, for example, the species composition of the ecosystems. Climatic warming might force many species of the boreal zone into extinction. Even the gaining species might not respond in the manner extrapolated from Figure 1 in the case of a rapid change to a warmer climate. The calculated growth responses, both absolute and relative, are likely to be overestimated because adaptation to a new climate takes time.

All data used in the analysis are from Finland, and we are certain of their accuracy. However, although Finland clearly belongs to the boreal zone, it covers only about $5 \%$ of the entire zone, so that not all conditions in the zone are 


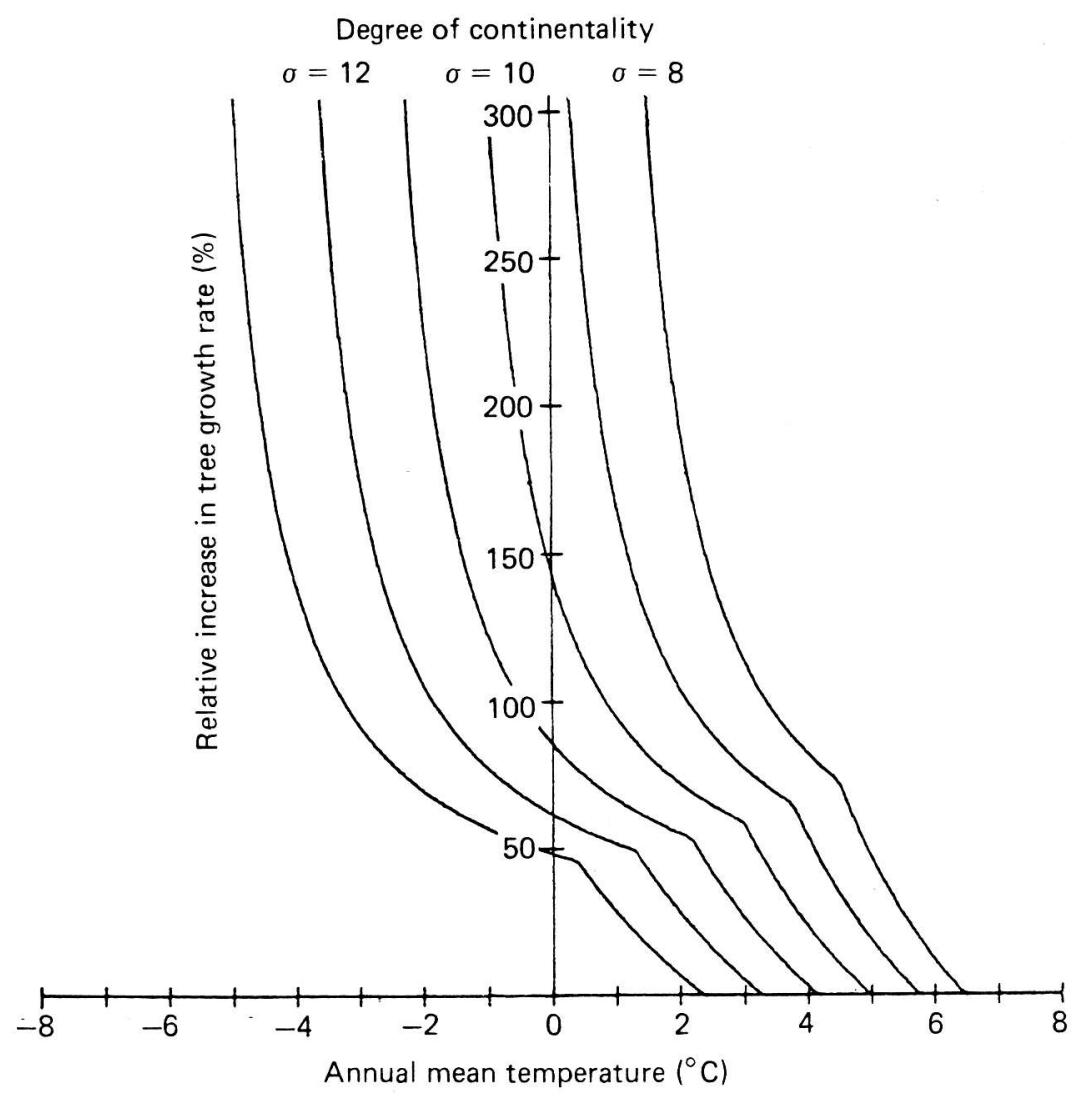

Fig. 5. As in Figure 4, but with the increase in growth rate expressed in relative terms.

adequately represented by the data. In particular, the continental extremes are not represented.

The method relies heavily on the relationship of Equation (2), which converts ETS values into approximate growth rates. Different regressions might be needed for other areas with different plant species, soils, and land management practices. The assumption of constant growth with high-ETS conditions may need reexamination. However, the qualitative findings of this study should remain the same for a range of similar growth functions.

\section{References}

Arnold, C.Y.: 1959, 'The Determination and the Significance of the Base Temperature in a Linear Heat Unit System', Proc. Am. Soc. Hort. Sci. 74, 430-445.

Arovaara, H., Hari, P., and Kuusela, K.: 1984, 'Possible Effect of Changes in Atmospheric Composition and Acid Rain on Tree Growth: An Analysis Based on the Results of Finnish National Forest Inventories', Commun, Inst. For. Fenn. 122. 
The Global 2000 Report to the President: 1980, Vol. 2, U.S. Council on Environmental Quality.

Hämet-Ahti, L.: 1981. 'The Boreal Zone and its Subdivision', Fennia 159, 69-75.

Heino, R. and Hellsten, E.: 1983, 'Climatological Statistics in Finland', Meteorological Yearbook of Finland, Vol. 80, Part 1a.

Kolkki, O.: 1969, 'Overview of the Climate in Finland', Report No. 18, Finnish Meteorological Institute (in Finnish).

Manabe, S. and Stouffer, R.J.: 1980, 'Sensitivity of a Global Climate Model to an Increase of $\mathrm{CO}_{2}$ Concentration in the Atmosphere', J. Geophys. Res. 85, 5529-5554.

Mikola, P.: 1950, 'On Variations in Tree Growth and their Significance to Growth Studies', Commun, Inst. For. Fenn. 38, 5.

Mukula, J., Rantanen, O., and Lallukka, U.: 1978, 'Crop Certainty of Oats in Finland 1950-1976', Report No. 10, Agricultural Research Centre, Department of Plant Husbandry, Jokioinen (in Finnish).

Sarvas, R.: 1972, 'Investigations on the Annual Cycle of Development of Forest Trees. Active Period', Commun. Inst. For, Fenn, 76, 3.

Yearbook of Forest Statistics: 1983, Official Statistics of Finland, Vol. XVIIA, No. 14; Folia Forestalia $\mathbf{5 5 0}$. 